RODOVIA BR-163: ENTRE A GEOPOLÍTICA E A GEOECONOMIA

\title{
RODOVIA BR-163: ENTRE A GEOPOLÍTICA E A GEOECONOMIA
}

\author{
Thiago Oliveira Neto \\ Mestrando do Programa de Pós-graduação em Geografia - UFAM \\ Universidade Federal do Amazonas \\ thiagoton91@live.com \\ Ricardo Jose Batista Nogueira \\ Professor Doutor do Programa de Pós-graduação em Geografia - UFAM \\ Universidade Federal do Amazonas \\ nogueiraricardo@uol.com \\ Hervé Émilien Rene Théry \\ Professor Doutor do Programa de Pós-graduação em Geografia Humana - CNRS/USP \\ hthery@aol.com
}

\begin{abstract}
RESUMO: A produção e a circulação de mercadorias dependem, de maneira primordial, da existência de sistemas de engenharia que permitam a fluidez, pelo território, de veículos capazes de efetuar o deslocamento de uma dada produção de um ponto para outro, seja para atender demandas locais ou globais, associadas à produção e ao consumo. Nesse contexto, insere-se a produção de grãos no Brasil, com destaque para a soja e o milho, que tiveram sua produção deslocada ao longo dos últimos 50 anos para o Norte do Brasil. A produção desses grãos engloba desde a plantação até o escoamento das safras, demandando cada vez mais a presença de infraestruturas públicas, em destaque as rodovias construídas pelo Estado, concomitantemente, a presença de capital privado na estrutura de portos de transbordo, veículos, embarcações e silos. Nesse sentido, destaca-se o papel fundamental da rodovia BR-163 e a instalação de portos no município de Itaituba.
\end{abstract}

Palavras chave: circulação, grãos, território.

\section{INTRODUÇÃO}

A produção de grãos de uma agricultura tecnificada engloba o emprego da ciência nas alterações genéticas e os melhoramentos do solo para permitir a produção em regiões antes não produtoras de grãos, atendendo, em sua maioria, com maior ênfase, as demandas do mercado externo asiático. Essa produção acompanhada pelo seu deslocamento, a rigor, engloba um complexo logístico que forma um arranjo espacial, constituído de interações espaciais, formadas pelo deslocamento de cargas.

Uma das principais infraestruturas que permitem o deslocamento da produção de grãos no Brasil são as rodovias, construídas em grande número entre as décadas de 50 e 70 com objetivo de romper os isolamentos das regiões e permitir uma integração territorial, tendo ocorrido o deslocamento da frente pioneira com incentivos do Estado.

No século XX e início do XXI algumas ações do Estado, através de políticas territoriais, almejavam a consolidação dos eixos de integração, com destaque para a rodovia BR163, construída na década de 70, com o objetivo de consolidar mais um corredor logístico, porém, até hoje, sem pavimentação em sua totalidade. Atualmente, esse 
RODOVIA BR-163: ENTRE A GEOPOLÍTICA E A GEOECONOMIA

eixo rodoviário está se tornando um dos principais elos entre o Mato Grosso e os portos da bacia amazônica, ocasionando um redirecionamento de fluxos de veículos transportadores de grãos e demais cargas entre o Centro-Oeste e a bacia amazônica.

Posto isso, neste texto aborda-se que o deslocamento geográfico da produção de grãos se desdobra a partir da existência ou da instalação de infraestruturas de circulação, que permitam e facilitem o escoamento da produção e a importação de insumos agrícolas, alterando, substancialmente, os arranjos espaciais existentes no território.

Para permitir o deslocamento da produção com uma redução do percurso de trajeto rodoviário e marítimo, parte dos grãos começou a ser transportadas para a região amazônica, onde se encontram as infraestruturas instaladas, primeiro a hidrovia do rio Madeira, com portos em Porto Velho e Itacoatiara e, atualmente, com portos concentrados no eixo da BR-163 e BR-230, com destaque para: Miritituba e Santarém, e em outra parte da Amazônia, incluindo os portos de Santana e Barcarena, que completam o transporte hidroviário dos grãos.

\section{MATERIAIS E MÉTODOS}

Para o desenvolvimento desta pesquisa, optou-se em realizar primeiramente: um levantamento em jornais e livros sobre a construção da rodovia BR-163 e o discurso geopolítico constituído na década de 70; posteriormente realizou-se: um segundo levantamento bibliográfico, referente a pavimentação da rodovia, planos de ordenamento territorial e a instalação de estruturas portuárias nos acessos rodoviários conectados com a BR-163.

\section{RESULTADOS E DISCUSSÃO}

A produção de soja, antes concentrada no Sul do Brasil, foi sendo cultivada entre as décadas de 70 e 80 , no Centro-Oeste, no bioma de cerrado, até então considerado de baixa fertilidade, com solos não utilizados, mas que, com a aplicação de pesquisas agronômicas, corrigindo a acidez e a inserção de novas variedades de grãos (MELLOTHÉRY, 2011), e na década de 90, essa frente de expansão alcançou os limites geográficos desse bioma (THÉRY, 2004a) e, atualmente, a produção de grãos ocorre em porções setentrionais da Amazônia, como é o caso de Roraima e Amapá, além da ainda, expansão do cultivo de grãos para os estados do Maranhão, Tocantins, Piauí e Bahia se constituindo uma porção territorial denominada de Matopiba.

Os mapas a seguir (Fig. 1) permitem visualizar o movimento da expansão da produção de soja e milho ao longo dos últimos anos, com um direcionamento que parte da região Sul em direção ao Norte, sendo que, no caso do Mato Grosso, a expansão ocorre no eixo da rodovia BR-163, repercutindo em problemas logísticos, enfrentados pelos produtores de grãos no período de colheita das safras. Esses problemas relacionam- 
RODOVIA BR-163: ENTRE A GEOPOLÍTICA E A GEOECONOMIA

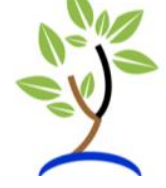

se, principalmente, ao deslocamento da produção para o norte ocasionou um distanciamento de parte da região produtora de grãos aos principais portos exportadores (THÉRY, 2004a; 2014), com destaque para Santos (SP) e Paranaguá (PR), tendo ainda o porto de Rio Grande, que praticamente foi concebido para receber a produção graneleira que se concentrava na região Sul, na década de 70 e, atualmente, concentra-se no Centro-Oeste. Nesse contexto, Becker destaca que a estruturação dos transportes multimodais é fundamental no comércio mundial, e ressalta que "a proximidade das áreas produção em relação aos portos constitui um elemento territorial decisivo na definição da competitividade" no mercado, incluindo nesse aspecto, a pavimentação de mais de 1000 km da BR-163 (2009, p. 100).

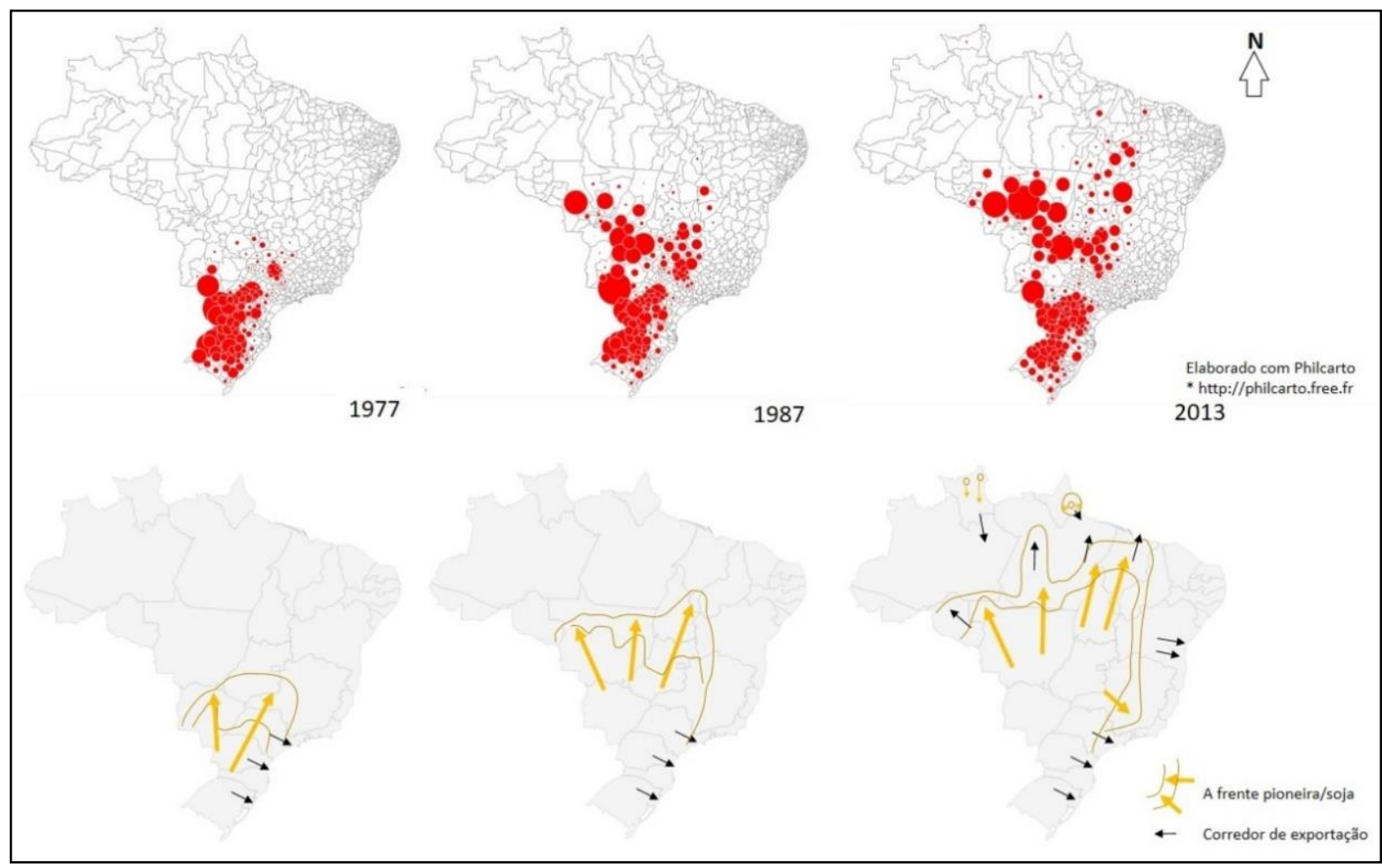

Figura 1. Representação de três momentos históricos da produção de soja no Brasil, evidenciando o deslocamento da produção para a Amazônia. As setas pretas representam os principais eixos terrestres de deslocamento do transporte da soja. O círculo vermelho representa a concentração da produção. Software: Philcarto e PowerPoint. Fonte: IBGE. Org: Neto, T. O.

Em outra escala, houve uma alteração espacial no município de Itaituba, com destaque para 0 distrito de Miritituba ${ }^{1}$, onde se concentram as Estações de Transbordo de Carga-ETC. A construção dessas ETC,s foi acompanhada pela

\footnotetext{
${ }^{1} \mathrm{O}$ distrito de Miritituba passou a receber investimentos privados nos portos e também na construção de um residencial Jardim Tapajós estando instalado nas proximidades das ETC,s.
} 
RODOVIA BR-163: ENTRE A GEOPOLÍTICA E A GEOECONOMIA

\section{签}

materialização de outras infraestruturas, tais como, pontos de parada e postos de combustíveis, operacionalizadas nos últimos quatro anos.

\section{CONSIDERAÇÕES}

No decorrer do processo de pavimentação da rodovia BR-163, pode-se apontar que se redirecionam não apenas os fluxos das cargas graneleiras, mas também as dinâmicas do território, como a expansão da frente pioneira, o aumento demográfico em cidades já estabelecidas e a formação de novas ocupações, prostituição, mineração em diversas escalas e em diversos métodos de extração, novas usinas hidrelétricas e por fim, não menos expressivo à expansão dos impactos ambientais.

As alterações territoriais para o deslocamento da produção não ocorreram apenas nas áreas produtoras ou nas margens dos rios onde se instalaram os portos graneleiros, mas também nas áreas onde é realizado o desembarque marítimo final da produção de grãos, a qual passou por marcantes transformações com a implantação de um conjunto de objetos geográficos e de elevada tecnificação, para realizar as operações diárias de transportes. O destaque nesse caso é dado aos portos estrangeiros, situados na Europa, em Roterdã na Holanda, e a maior concentração de portos cargueiros do mundo na Ásia, com destaque para China, que de forma geral, foram estruturados para os fluxos internacionais.

Nesse contexto, nota-se que a preparação para colocar a mercadoria em movimento e acelerar esse movimento circulatório do capital, ocorre tanto na área produtora quanto na receptora da produção de grãos, que depois passam por processos de transformação e inserção nos mais diversos alimentos e até medicamentos.

\section{REFERÊNCIAS}

BECKER, B. Amazônia: Geopolítica da virada do III milênio. Rio de Janeiro: Garamond, 2009.

MELLO-THÉRY, N. A. Território e gestão ambiental na Amazônia: terras públicas e os dilemas do Estado. São Paulo: AnnaBlume, 2011.

THÉRY, H. Modelização gráfica para a análise regional: um método. Geousp, v. 15, 2004b, pp. 179-188.

THÉRY, H. Modelização gráfica para análise regional: um método. Geousp: Espaço e Tempo, no 15, pp. 179-188, 2006.

THÉRY, H. Um gigante do agronegócio em Mato Grosso, Espaço e Economia, v. 5, 2014. 
RODOVIA BR-163: ENTRE A GEOPOLÍTICA E A GEOECONOMIA

NETO, T. O; NOGUEIRA, R. J. B.. A geopolítica rodoviária na Amazônia: BR-163 / Santarém-Cuiabá. Revista de Geopolítica, v. 6, p. 1-21, 2015.

NETO, T. O; NOGUEIRA, R. J. B.. Alguns apontamentos das práticas espaciais ao longo da BR-163 (Santarém-Cuiabá). Revista Geonorte, v. 8, p. 31-50, 2017. 